\title{
The Factors Affecting Organizational Innovativeness
}

\author{
Napaporn Tuksinnimit \\ Technopreneurship and Innovation Management Program \\ Graduate School, Chulalongkorn University \\ 1405-1409 14th Floor, Chamchuri Square Building \\ Phayathai Road, Pathumwan Bangkok 10330, Thailand \\ Tel: 66-2657-6334 E-mail: knottucs47@gmail.com
}

\author{
Supol Durongwatana \\ Department of Statistics, Faculty of Commerce and Accountancy \\ Chulalongkorn University \\ 8th Floor Mahitaladhibesra Building, Phayathai Road, Pathumwan \\ Bangkok 10330 Thailand \\ Tel: 66-2218-5655Ｅ-mail: Supol@cbs.chula.ac.th \\ Pakpachong Vadhanasindhu \\ Department of Commerce, Faculty of Commerce and Accountancy \\ Chulalongkorn University
}

Chaisombat2 Building, Phyathai Road, Pathumwan, Bangkok 10330 Thailand

Tel: 66-2218-5758Ｅ-mail: Pakpachong@hotmail.com

Received: November 17, 2014 Accepted: December 14, 2014 Published: February 1, 2015

doi:10.5296//jmr.v7i2.7013 URL: http://dx.doi.org/10.5296/jmr.v7i2.7013

\begin{abstract}
This paper aimed to explore the determinant factors to affect the capability to innovate organization and used method to gather the data on agency of US. Foreign Missions in Thailand. The finding revealed that the survey from employees understood the concept of
\end{abstract}




\section{Macrothink}

Journal of Management Research

ISSN 1941-899X

2015, Vol. 7, No. 2

innovation. In the quantitative section involved collecting data from 270 employees by questionnaire. The results showed mean of the factors to affect organizational innovativeness is rather high level, commitment to learning, Customer focus, management support, organizational structure, knowledge sharing, contingency reward. This implies that all factors were important and that organization is moving to innovative organization.

Keywords: Innovation, Organizational Innovativeness, Learning Organization 


\section{Introduction}

The Foreign Missions in Thailand are 75 diplomatic corps. The diplomatic corps may, in certain contexts, refer to the collection of accredited heads of mission (ambassadors, high commissioners, and others) who represent their countries in another state or country. As a body, they usually only assemble to attend state functions like a coronation, inauguration, national day or State Opening of Parliament, depending on local custom. They may also assemble in the royal or presidential palace to give their own head of state's New Year greeting to the head of state of the country in which they are based.

The U.S. Foreign Mission in Thailand is one of the largest in the world and is comprised of several dozen sections and agencies. The mission is to advance the interests of the United States, and to serve and protect U.S. citizens in Thailand. The foreign mission reports and analyzes developments in Thailand of concern to the United States, and advances a broad range of U.S. policy initiatives. The foreign mission promotes United States' economic and commercial interests, and the export of American agricultural and industrial products and services, and otherwise assists American business, workers and investors. The foreign mission engages the government and a broad range of organizations and individuals in Thailand to promote shared values. Among others, these include individual freedom, human rights and democracy and the rule of law. The U.S. Foreign Mission will be a values-based organization where engaged employees dedicated to integrity, unity, creativity and responsibility build trust and promote U.S. interests in Thailand, across the region and around the globe. In This paper the authors found that most of the research is to study the ability of the organization to build innovations that looks at a company, government agency, educational. That no research on the Foreign Missions diplomatic corp is an agency of the U.S. government. The focus is on innovation and organizational innovation. This is what the authors want to learn and study because the authors believe that having the ability to create an innovative organization. Is to find innovative strategies used and are constantly used to create sustainability for the organization. Organizations cannot innovate themselves. The primary function of the organization is to encourage individuals and teams who want to do innovative and creative changes that will lead to improvements in the organization. The organization will promote innovative components and systems requires several factors. Organizational innovation, each organization will have a unique design that is featured and different, which is the result of a combination of factors come together, but innovation is what will happen, we rely on many factors to encourage innovation. occur Is why the authors who want to study the factors that affect the ability to create innovative organizations to contribute to the organization of innovation. This study developed a conceptual framework, based on the concept of perspective only valuable resource of the organization and the concept of the learning organization to create a variable in the research and explain the link between factors involved as well. Organizational learning Human Resource Management Includes environment within the organization that affects its ability to innovate. By giving priority to focus on valuable resources of the organization. If these resources are available Organizations can create a competitive advantage and lead to higher performance. The research in this study enables organizations to build capacity for innovation, and recognizing and factors involved 
in the development of relevant and essential to innovation. Including a better understanding of the link between factors that affect the ability to create innovative organizations to lead the next innovation organizations.

The aimed of this paper is to explore the determinant components to affect the capability to innovate of The Foreign Missions in Thailand. The paper is divided into five parts; the first part is introduction, the second part is the literature review, the third part is methodology. The fourth part reports the findings, and the last part presents come concluding comments.

\section{Literature review}

Especially with the business to be competitive and to survive. The success of such a competition to make the business a success and ability to compete, sustainable businesses that need to make their organization is an organization of innovation and organizational innovation will result. innovation in various forms to create sustainable business advantage to the next, which in this chapter is to understand the capabilities of the innovative organization. Including theory and related concepts include. Conceptual perspective only valuable resource of the organization. Organizational learning and innovation. The idea was to develop a conceptual framework for research.

The importance of innovation in organizations occurred in the last century 1950 study of drucker (1959) and Drucker (1954) is a scholar of the first to focus on innovation and reflect the neglect of research on innovation. organizational level The research on innovation capabilities organizations can mainly be found in the literature on the diffusion of innovation (Innovation Diffusion) (Rogers, 1995) suggest that organizations need to innovate to enable organizations to survive in that environment. a variance greater innovation, innovation has been more interest as a factor in making the organization successful (Cohen and Levinthal, 1990); Leonard-Barton, 1995; Brown and Eisenhardt, 1997; McGrath, 2001; Tsai, 2001) to explain the cause for more innovative products and new technologies. And allows organizations to make a difference. Adaptation and presentation of the organization in new ways (Shoonhoven, Eisenhardt and Lyman, 1990), which currently has several innovative organizational forms such as. Business models (Business Model) Product (Product) Service (Service) process (Process) or channel (Channel) (Carr, 1999) such innovations are used to meet customer needs. To differentiate from the competition and allows organizations to survive and create a sustainable environment are variable and extremely complex (Freeman, 1994; Lawless and Anderson, 1996; Eisenhardt and Brown, 1999) in. Education Innovation Most researchers focus on the type of innovation. Research and development to create economically. And the diffusion of innovation (Miles and Snow, 1978; Freeman, 1974; Van de Ven, Polley, Garud and Venkataraman, 1999) Tushman (1997) explains that the long term success of the organization need to target innovation level. organizations to build capacity to contribute to innovation. Some scholars explain that innovation is rushing to create something new each employee (Rogers and Shoemaker, 1971; Hurt, Joseph and Cook, 1977; Hurt and Teigen, 1977) in this sense. A new innovative research to focus on individuals, not organizations by Roger and Shoemaker (1971) for one person or one group of people who bring ideas or new technology deployment that. People or groups with innovation. What new 
creations must be new compared to other people or other groups. While the definition of innovative organizations Hult (1998) gives a clear description of it. Innovation is an open mind to new ideas in the perspective of organizational culture. The organization is focused on innovation, dedicated resources to create a superior product (Berthon, Hulbert and Pitt, 1999). Innovation is the concept of the overall organization of innovation (Hurley and Hult, 1998) is the ability to recommend products. Process or new ideas of the people in the organization (Damanpour, 1991) were selected using the ideas or behavior concerns. Systems, processes, policies, program products or services that are new to the organization (Zaltman et al., 1973), while Wang and Ahmed (2004) provides a definition of innovation is the ability to create innovative overall. organizations in creating new products to the industry. Or opening new markets through strategic focus on the behavior and organization and on the innovation, the innovation, the organization has been critical to the organization's survival clear picture environment has changed (Rogers and Shoemaker, 1971; Damanpour, 1991.; Rogers, 1995) by the management with innovative solutions to organizational survival and success of the organization (Hult et al., 2004). Hurt et al. (1977) explains that organizations with innovation. The nature of the organization with the intention of changing. This innovation is a critical component. The innovations (Openness to Innovation) (Zaltman et al., 1973) and the ability to innovate (Capacity to innovate) (Burns and Stalker, 1977) Hurley and Hult (1998) explains that innovation. Organization is open to new ideas in the field of organizational culture perspective. The focus on the purposes it is the duty of the organization to delivering innovation to deliver the value that happens to customers (Homburg, Hoyer and Fassnacht, 2002), while the ability of innovation is capable of. organizations in adopting new ideas or processes used. The intention of the innovation (Intention to be Innovative) is a component of the organization's focus on innovation (Kundu and Katz, 2003). Organizations need to innovate constantly. Because innovation is vital in enabling organizations to create a competitive advantage from having the operation at higher (Porter, 1990; Damanpour, 1991; Henard and Szymanski, 2001) to make innovation achieved result. operations for better or productive for the organization. Allows organizations to achieve their profitability. The growth of the market share. Or create success in the strategic objectives of the organization (Damanpour, 1991), resulting from an innovative approach to organizational change in response to changes in the internal or external environment and the organization has to prepare the environment to change. This innovation is an ongoing process. The application of knowledge to create a new product or service (Roper and Love, 2004) However, the management is of the opinion that in many organizations. It is difficult to achieve sustainable innovation (Department of Trade and Industry, 2000); Katila and Ahuja, 2002), innovative organizations have workers who are searching for useful information continuously. This organization will focus on responding to customer needs. While the organization's ability to innovate without losing time and resources in the education market. I cannot convert this knowledge into practice is (Hult et al., 2004). Conceptual perspective valuable resource of the organization only makes the growth and profitability of the organization is sustainable by being referred to in strategic research and economics that have been accepted as the education of Ricardo (1817). , Schumpeter (1934), Penrose (1959), Ansoff (1965) and Andrew (1971), which reflects the importance of the resource as well. Resources are defined as Is both 
tangible and intangible within the organization (Caves, 1980) Examples of resources include brand awareness employing skilled staff and a practice more efficient and cost (Wemerfelt, 1984). resource is the basis of the ability to make a profit and a source of talent, organizational resources and capabilities within the guidelines in the strategy of the organization in the long run (Grant, 1991) resource contains assets (Asset). and capabilities (Capability) assets as inputs in the production process. The talent is the ability (Ability) to redeploy assets into valuable products and services. And group internal resources as well as a part of the operational guidelines. The ability to change The adoption Response to changes or add value to the organization, which comes from skills and capabilities. Creating an experience The learning process or to gather and process work. Ability as a source of competitive advantage (Siripong Preutthipan, 1999) as well as Grant (1991), noting the difference between the resources and capabilities. Resources as a basis for the ability to make a profit. And as inputs in the production process. Resources of each organization, including main equipment. Employee skills, patents, and financial brands. Which by its own resources With little resources, we achieve results desired by the organization, the activities that cause such results requires collaboration and coordination among groups of resources. While the ability is the ability for a group of resources to run or do some activities. Resources are inputs that are controlled and used by organizations to develop and implement strategies used. Factor is the ability to coordinate resources and make the operations (Amit and Schoemaker, 1993; Rao, 1994) can be a valuable resource and a means of organization. Resources and capabilities that are valuable to the organization for a potential to add value to their advantage in the race or Amit and Schoemaker (1993) called strategic assets (Strategic Asset) derived from the needs of the buyer or the. market demand to influence the organization. (Bamey, 1986a) or created through experience are accumulated and continuous learning by practice (Learning by doing) (Dierickx and Cool, 1989; Reed and DeFillippi, 1990; Cool and Dierickx, 1994) samples. valuable resources and capabilities, including famous relationships with buyers and suppliers. Knowledge is not demonstrated manifest. Expertise in research and development and technological capabilities (Barney, 1991; Mahoney and Pandian, 1992; Rao, 1994; Schoemaker and Amit, 1994) is the conclusion. Resources as a source of talent to the organization. And talent is the most important source of competitive advantage. The primary function of the concept perspective valuable resource of the organization to determine specific strategy is to create sustainable benefits to occur by taking advantage of the resources available through the organization. Organizational learning is the organization of the event extensively to create and use knowledge to achieve competitive advantage. Including obtaining and sharing information about customer needs. Changes in the market and the performance of competitors. Which led to the development of new technologies. To create new products that are superior to competitors (Hurly and Hult, 1998; Moorman and Miner, 1998: Mone et al., 1998) focused learning influence the type of information that needs to be collected (Dixon., 1992) and this information needs to be interpreted (Argyis and Schon, 1978) to evaluate (Sinkula et al., 1997) and the exchange of knowledge (Moorman and Miner, 1998). Organization of learning need to focus on communication and dissemination of knowledge are included. Creating an atmosphere where memories of the organization and to gain access to, for example, the cause of learning activities is little within the organization 
due to events that occur often an important part of learning to use. Communication is an exchange of knowledge that each employee discovered (Jelnik, 1979) related to such ideas Cohen (1991) found that organizations with information that is in the process of learning and applying the skills that are sedentary. Therefore, the focus of the necessary sub-process of the acquisition, which carry information (Information Acquisition) (Sinkula, 1994a; Slater and Narver, 1994b, 1995) focused on learning can be integrated into one with that idea. To do Members of the organization develop knowledge meaningful to do better next time. Experience of each member contribute to the knowledge of the organization. And the understanding of the interaction between the organization and its environment better (Kerin, Mahajan and Varadavajan, 1990).

\section{Research questions}

What is the factors affecting organizational innovativeness?

\section{Objectives of research}

To study an explore the determinant to affect the capability to create organizational innovativeness.

\section{Objectives of research}

H1: Organizational environment and human resource management has an indirect influence on the ability to create innovation through learning organization and knowledge management.

$\mathrm{H} 2$ : Organizational environment of an indirect effect on the ability of the organization through innovative human resource management.

\section{Research Methodology}

The goal of this research is examined the factors that affect its ability to innovate population is used in this study employees of Foreign Missions in Thailand. The research design of this research is quantitative research Method. The population for this study is one of the employees of Foreign Missions in Thailand, All three agencies are agencies in Thailand. Reason for choosing this population because the goal of this research is. Examined the factors that affect its ability to innovate. The survey of employees Foreign Missions in Thailand, locations of various departments in the organization. Source of information which is used in this study. in Thailand, All three agencies have large units, a total of 1,000 employees by means of selecting a probability sample techniques by setting the tolerance level of 0.05 with a multi-stage sampling technique. The samples were 286 employees in all agencies selected with the multi-state sampling technique. The quantitative collection consisted of an employee opinion survey concerning the components affecting the ability to create innovative organizations. The samples were 286 employees in all agencies selected with the multi-state sampling technique. Table 1 shows the sample distribution. Most respondents were female (N $=164)$, graduated from master degree $(\mathrm{N}=212)$. An average of $42.6 \%$ of employees were FSN 8 - FSN 10 and $32.6 \%$ of employees had stayed with the organization from 11-15 years. 
Table 1. This is a Sample Distribution Table

\begin{tabular}{lcc}
\hline \multicolumn{1}{c}{ Topics } & $\begin{array}{c}\text { Number } \\
\text { of } \\
\text { Employees }\end{array}$ & Percentage \\
\hline Gender & 106 & 39.3 \\
Male & 164 & 60.7 \\
Female & & \\
Education & 51 & 18.9 \\
Bachelor Degree & 212 & 78.5 \\
Master Degree & 7 & 2.6 \\
Doctoral, Phd. Degree & & \\
Work Period & 36 & 13.3 \\
Less than 5 Years & 74 & 27.4 \\
5-10 Years & 88 & 32.6 \\
11-15 Years & 72 & 26.7 \\
More than 10 Years & & \\
Position & 109 & 40.4 \\
FSN 5 - FSN 7 & 115 & 42.6 \\
FSN 8 - FSN 10 & 46 & 17.0 \\
FSN 11 - FSN 13 & & \\
& & \\
\hline
\end{tabular}

\section{Findings}

Employees were surveyed concerning the components affecting the ability to create innovative organizations : (Organization Environment: Support the transformation of the organization, Having adequate resources, Focusing on the needs of the customer, Collaboration between agencies), (Learning Organization and Knowledge Management: To commitment, A shared vision, Open Minded, The exchange of knowledge within the organization), and (Human Resource Management: The recruitment process for a person to hold the position, Development training, Evaluation of performance, Rewarding circumstantial) A Likert scale ranging from 1 (fully disagree) to 4 (fully agree) was used for the measurement. Table 2 shows the means and standard deviation of the components affecting the ability to create innovative organizations. The employees responses ranged. The high value was for Having adequate resources of $(\bar{x}=3.47)$, followed by The recruitment process $(\bar{x}=3.34)$, Training Development $(\bar{x}=3.23)$, Organization structure $(\bar{x}=3.21)$, Evaluation of performance $(\bar{x}=3.10)$, Focusing on the needs of customers $(\bar{x}=3.02)$, Evaluation of performance $(\bar{x}=3.10)$, Support the transformation performance $(\bar{x}=2.93)$, Collaboration between agencies $(\bar{x}=2.87)$, Rewarding circumstantial $(\bar{x}=2.86)$, The exchange of knowledge with organization $(\bar{x}=2.78)$, and open minded $(\bar{x}=2.56)$. This suggests that all components were somewhat. 


\section{Macrothink}

Journal of Management Research

ISSN 1941-899X

2015, Vol. 7, No. 2

Table 2. This is a Means and Standard Deviation of the components affecting the ability to create innovative organizations

\begin{tabular}{lll}
\hline \multicolumn{1}{c}{ Components } & Mean & \\
\hline Organization Environment & & \\
Organization Structure & 3.21 & 0.63 \\
Support the transformation of the organization & 2.93 & 0.52 \\
Having adequate resources & 3.47 & 0.54 \\
Focusing on the needs of the customers & 3.02 & 0.63 \\
Collaboration between agencies & 2.87 & 0.51 \\
Learning Organization and Knowledge Management & & \\
To commitment & 2.80 & 0.67 \\
A shared vision & 3.09 & 0.57 \\
Open Minded & 2.56 & 0.58 \\
The exchange of knowledge within the organization & 2.78 & 0.57 \\
Human Resource Management & & \\
The recruitment process for a persons to hold the position & 3.34 & 0.59 \\
Development training & 3.23 & 0.60 \\
Evaluation of performance & 3.10 & 0.52 \\
Rewarding circumstantial & 2.68 & 0.69 \\
& & \\
\hline
\end{tabular}

When we tested the sample characteristics and the components affecting the ability to create innovative organizations we found that all components affecting the ability to create innovative organization were significant. Correlation analysis were used in the analysis. The multivariate analysis techniques used in this study is the analysis and multinomial regression assumptions is that all the variables must be independent of each other. The relationship between the variables in the same equation is not much $(r<.75)$ (Suchart, 2005 ) by the correlation coefficients between the variables used in the analysis ability to create innovative. 
Table 3. This is a descriptive statistics and the correlation coefficients between the variables used in the analysis of the innovation

\begin{tabular}{|c|c|c|c|c|c|c|c|c|c|c|c|c|c|}
\hline & leadercha & orgstruc & Resource & custinex & relaunit & commit & sharevis & openmind & $\mathrm{km}$ & recruit & train & evalu & reward \\
\hline orgstruc & $.490^{*}$ & & & & & & & & & & & & \\
\hline resource & $.291^{*}$ & $.179^{*}$ & & & & & & & & & & & \\
\hline custinex & $.387^{*}$ & $.464^{*}$ & $.313^{*}$ & & & & & & & & & & \\
\hline relaunit & $.402 *$ & $.484 *$ & $.306 *$ & $.326^{*}$ & & & & & & & & & \\
\hline Commit & $.324^{*}$ & $.092^{*}$ & $.310^{*}$ & $.473^{*}$ & $.112^{*}$ & & & & & & & & \\
\hline Sharevis & $.400^{*}$ & $.372^{*}$ & $.163^{*}$ & $.467^{*}$ & $.516^{*}$ & $.201^{*}$ & & & & & & & \\
\hline openmind & $.105^{*}$ & $.036^{*}$ & $.166^{*}$ & $.212 *$ & $.114 *$ & $.109^{*}$ & $.155^{*}$ & & & & & & \\
\hline $\mathrm{km}$ & $.384^{*}$ & $.150^{*}$ & $.093^{*}$ & $.481^{*}$ & $.159^{*}$ & $.417^{*}$ & $.289^{*}$ & 0.42 & & & & & \\
\hline recruit & $.392^{*}$ & $.215^{*}$ & $.400^{*}$ & $.486^{*}$ & $.548^{*}$ & $.179 *$ & $.517 *$ & $.189^{*}$ & $.448^{*}$ & & & & \\
\hline train & $.614^{*}$ & $.624^{*}$ & $.259^{*}$ & $.375^{*}$ & $.644^{*}$ & $.111^{*}$ & $.542^{*}$ & .037 & $.221^{*}$ & $.435^{*}$ & & & \\
\hline evalu & $.452^{*}$ & $.441^{*}$ & $.206^{*}$ & $.114^{*}$ & $.371^{*}$ & $.120^{*}$ & $.551^{*}$ & $.170^{*}$ & $.014^{*}$ & $.221^{*}$ & $.487^{*}$ & & \\
\hline reward & $.484 *$ & $.544^{*}$ & $.223^{*}$ & $.378^{*}$ & $.635^{*}$ & $.178^{*}$ & $.644 *$ & $.145^{*}$ & $.101^{*}$ & $.343^{*}$ & $.609^{*}$ & $.517^{*}$ & \\
\hline inno & $.639 *$ & $.498^{*}$ & $.337^{*}$ & $.723^{*}$ & $.401^{*}$ & $.642 *$ & $.442 *$ & $.124 *$ & $.532^{*}$ & $.389^{*}$ & $.477^{*}$ & $.209 *$ & $.490^{*}$ \\
\hline Mean & 2.933 & 3.216 & 3.477 & 3.022 & 2.878 & 2.807 & 3.096 & 2.562 & 2.784 & 3.344 & 3.230 & 3.107 & 2.862 \\
\hline S.D. & .0523 & 0.636 & 0.540 & 0.638 & 0.518 & 0.678 & 0.576 & 0.583 & 0.571 & 0.596 & 0.604 & 0.524 & 0.695 \\
\hline
\end{tabular}

Table 3 results of the analysis showed employees embassy opinion that the organization has adequate resources (resource) and the recruitment process recruitment jobs (recruit) level, whose average 3.344 and 3.477 , respectively, with a population of such a training and development (train), performance evaluation (evalu) a shared vision (sharevis) focused response, Customer needs (custinex) to recognize and support the transition of administration (leadercha) collaboration between agencies (relaunit) for the award by the (reward) to make a commitment to learn (commit) exchange. knowledge within the organization $(\mathrm{km})$ and the Open Minded (openmind) is quite large with an average of 3.230, 3.107 , 3.096 , 3.022 , 2.933 , $2.878,2.807,2.807,2.784$, and 2.562 , respectively , including the organizational structure (orgstruc) is quite flexible, with an average of 3.216 by the variables with high affinity is open minded and rewarding situation. The correlation coefficient of 0.644 .

\section{Conclusion}

However, successful innovation is not easy, and it depends on several factors. This study aimed to explore the determinant to affect the capability to innovate and the components of the innovative organization and used method to gather the data on three big departments in agency of US. Foreign Missions in Thailand. The quantitative section involved collecting data from 270 employees via questionnaire. 
The finding revealed that the survey from employees of the US. Foreign Missions in Thailand. The Staff understood the concept of innovation, and all of components to affect the capability to innovate and the components of the innovative organization. When considering the quantitative data it was found that the mean of all factors (Customer focus is the most positive direct and indirect causes with the capability to innovate and next is Management support and attitude toward change, Commitment to Learning , Contingency Reward, Knowledge sharing within organization, Organizational Structure, Slack Resources and Inter functional Coordination). In addition to the factors already mentioned. There are some factors that affect direct and indirect causal negative is the ability to innovate that is Human source management of position selective recruitment process and Appraisal. This implies that all factors were important and that organization are moving to "Innovative Organization" need to adjust the paradigm by paradigm must focus on the recognition and support of the change of leadership. Organizational change to make a difference, adaptive learning and knowledge sharing. To establish a link between the private sector, government agencies and academia.

Finally, the employees mentioned the ability to create innovation, Organizations need to adjust the policy process within the organization since its innovation leadership with commitment. The direction for cooperation between agencies and a focus on customer needs, both internal and external. Restructuring the Organization Having adequate resources This must be done through the process of human resource management. The recruitment process for the selection of his tenure. Evaluation and rewards as a way to create a commitment to learning and sharing knowledge of the staff. Apart from the factors that affect its ability to innovate, as mentioned above. Creating the ability to create innovative organization. Organizations need to leverage their participation at all levels. To modify the work culture in the past. Executives need to focus on the change and require cooperation from agencies outside the public sector, private sector and academia to establish links and promote and improve knowledge Sharing. The exchange of knowledge transfer, network alumni and measure the success of the collaboration that occurs to organizational innovativeness and sustainable organizations.

\section{References}

Ahmed, P.K. (1998). Culture and Climate for Innovation. European Journal of Innovation Management, 1(1), 0-4.

Amit, R., \& Shoemaker, P. J. H. (1993). Strategic Assets and Organizational Rent. Strategic Management Journal, 14(1), 46.

Ansoff, H.I. (1965). Corporate Strategy: an Analytical Approach to Business Policy for Growth and Expansion. New York: McGraw-Hill.

Ansoff, H.I., \& Stewart, J.M. (1967). Strategies for a Technology Based Business. Harvard Business Review, 45(6), 71-8 .

Berthon, Pierre, Hulbert, James M., \& Pitt, Leyland F. (1999). To Serve or Create?: Strategic Orientations toward Customers and Innovation. California Management Review, 42(1), 7-58. http://dx.doi.org/10.2307/41166018 
Burns, Tom, \& Stalker, G.M. (1961). The Management of Innovation. London: Tailstock Publishing.

Caves, R.E. (1980). Industrial Organization, Corporate Strategy and Structure. Journal of Economic Literature, 58, 64-92.

Cohen, M. D., \& Sproull, L. S. (1996). Organizational Learning. Thousand Oaks, CA: Sage Publications.

Cool, K., \& Dierickx, I. (1994). Commentary: Investments in Strategic Assets: Industry and Firm-Level Perspectives. In Advances in Strategic Management, 10. P. Shrivastava, A. Huff and J. Dutton, eds. Greenwich, CT: JAI Press. Pp. 5-44.

Damanpour, F. (1991). Organizational Innovation: a Meta-Analysis of Effects of Determinants and Moderators. Academy of Management Journal, 4, 555-590. http://dx.doi.org/10.2307/256406

Danneels, E., \& Kleinschmidt, E.J. 2001. Product Innovativeness from the Firms' Perspective: its Dimensions and their Relation with Project Selection and Performance. Journal of Product Innovation Management, 18(6), 57-7. http://dx.doi.org/10.1016/S0737-6782(01)00109-6

Dixon, N.M. (1992). Organizational Learning: a Review of the Literature with Implications for HRD Professionals. Human Resource Development, 29-49.

Freeman, Chris (1994). Innovation and Growth. In Handbook of Industrial Innovation, Part I. Mark Dodgson and Roy Roth well, eds. Aldershot, UK: Edward Elgar Publishing. Pp. 78-9 .

Grant, R.M. (1991). The Resource-Based Theory of Competitive Advantage: Implications for Strategy Formulation. California Management Review, 114(1), 5.http://dx.doi.org/10.2307/41166664

Roper, S., \& Love, J. (2004). The Organization of Innovation: Collaboration, Cooperation and Multi-Functional Groups in UK and German Manufacturing. Cambridge Journal of Economics, 28, 1-18.

Siripong Preutthipan. (1999). The Impact of Firm-Specific Resources on Firm Performance under Different Ownership Structures. Doctoral dissertation, Chulalongkorn University.

Thomas, A.S., Litshert, R.J., \& Rahaswamy, K. (1991). The Performance Impact of Strategy-Manager Coalignment: an Empirical Examination. Strategic Management Journal, 12, 509-522. http://dx.doi.org/10.1002/smj.4250120704

Tsai, W. (2001). Knowledge Transfer in Intra-Organizational Networks: Effects of Network Position and Absorptive Capacity on Business Unit Innovation and Performance. Academy of Management Journal, 44(5), 996-1004. http://dx.doi.org/10.2307/3069443

Tushman, Michael L., \& O'reilly, Charles A. III. (1997). Winning through Innovation: a Practical Guide to Leading Organizational Change and Renewal. Boston: Harvard Business School Press. 


\section{Macrothink}

Journal of Management Research

ISSN 1941-899X 2015, Vol. 7, No. 2

Wang, C.L., \& Ahmed, P.K. (2004). The Development and Validation of the Organizational Innovativeness Construct Using Confirmatory Factor Analysis. European Journal of Innovation Management, 7(4), 0 -1.

Zaltman, G., Duncan, R., \& Holbek, J. (1973). Innovations and Organizations. New York: Wiley.

\section{Copyright Disclaimer}

Copyright for this article is retained by the author(s), with first publication rights granted to the journal.

This is an open-access article distributed under the terms and conditions of the Creative Commons Attribution license (http://creativecommons.org/licenses/by/3.0/). 